\title{
On the search for the amino acids on the lunar surface as it relates to other extraterrestrial bodies
}

\author{
Richard B. Hoover*a and Vera M. Kolb*b \\ ${ }^{a}$ Astrobiology Laboratory, NASA/Marshall Space Flight Center, National Space Science and \\ Technology Center, 320 Sparkman Dr., Huntsville, AL USA 35805 \\ ${ }^{b}$ Department of Chemistry, University of Wisconsin-Parkside, Kenosha, WI USA 53141-2000
}

\begin{abstract}
The early search for the amino acids on the lunar surface fines indicated such a low amount of the amino acids that it was deemed insignificant. While the later studies seemed to depart in some ways from the earlier results, they were not pursued. In this paper we critically evaluate the results from the Apollo missions from the new perspective with considerations of the sensitivity of the instrumentation available at the time. We discuss the possible relevance of the lunar results to the findings of the amino acids on the surfaces of other extraterrestrial bodies, such as Mars.
\end{abstract}

Keywords: amino acids, lunar surface, gas chromatography-mass spectrometry, ion-exchange chromatography, sensitivity of the measurements

\section{INTRODUCTION}

In this paper we revisit the evidence for and against the presence of the amino acids on the lunar surface, as measured on the samples from various Apollo missions. An extensive literature exists on this subject, including the methods that were used for these and related analyses (e.g. the meteorites and interstellar dust particles), as well as on the interpretation of data on the lunar amino acids ${ }^{1-27}$. The renewed interest in the further exploration of the Moon ${ }^{28}$ has been fueled by the recent discovery by Saul et al. ${ }^{29}$ of ancient water trapped within the interiors of tiny spheres (Fig. 1.a) of primitive lunar volcanic glass found in the "orange soil" (Fig. 1.b.) collected by Geologist Astronaut Harrison Schmidt in Shorty Crater of the Taurus-Littrow during the Apollo 17 Mission.

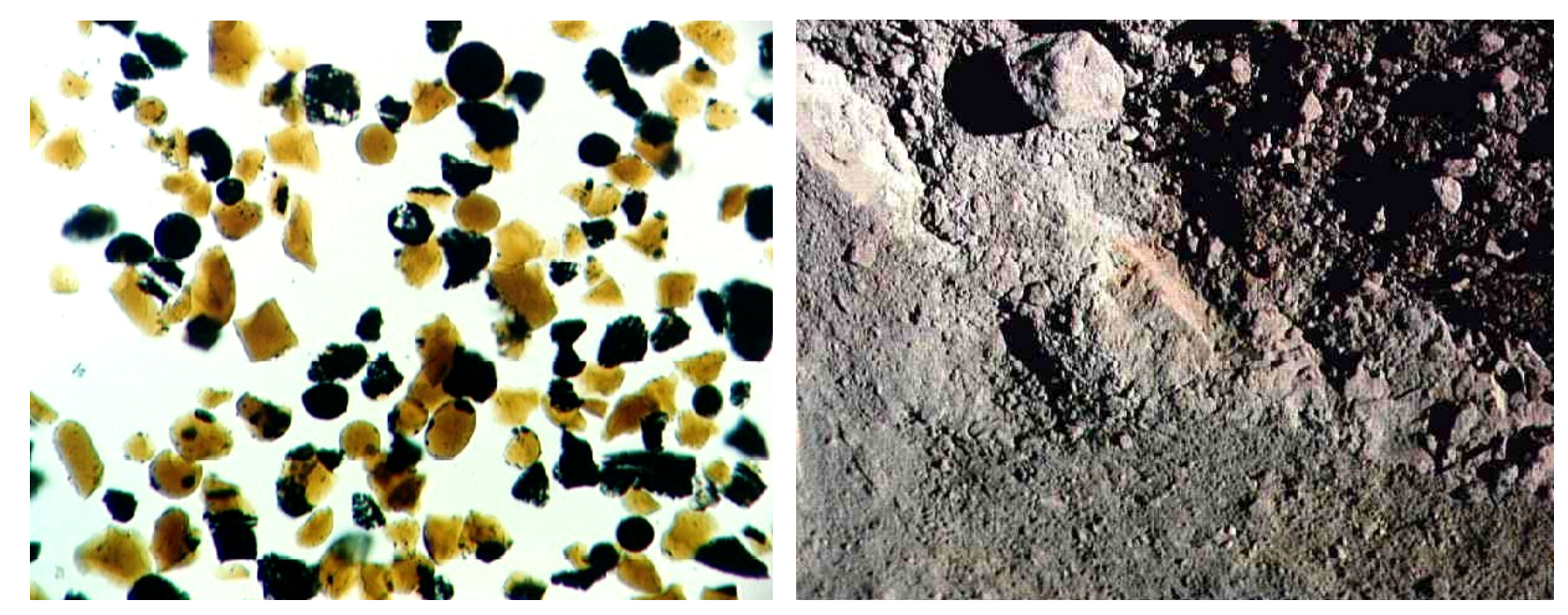

Fig. 1. a. Photomicrograph of 20-45 $\mu \mathrm{m}$ diameter water-bearing spheres found in the b. "Orange Soil" found during Apollo 17 in the Shorty Crater of Taurus-Littrow. Photo Courtesy NASA/LPL

Richard.Hoover@NASA.GOV: 1-256-961-7770; kolb@uwp.edu: 1262 595-2133; fax 1262 595-2056; 
Our interest in the re-examination of the presence of the amino acids on the lunar surface will hopefully draw attention to the early reports of search for other organic compounds on the Moon, namely porphyrins ${ }^{17,30-33}$, some of which were positive ${ }^{17,30,31}$.

\section{SEARCH FOR THE AMINO ACIDS IN THE LUNAR SAMPLES}

\subsection{Survey of the results}

The experimental results of the searches for the amino acids in the lunar samples from various Apollo missions fall into three categories. In the first category, the amino acids have been detected ${ }^{1-3,7-9,17,20}$. In the second category the amino acids have not been detected ${ }^{10,13,22}$. In the third category, the amino acids have been detected, but this presence was deemed to be an insufficient proof for the existence of the amino acids on the lunar surface ${ }^{5,6,11}$. Upon observing the presence of the amino acids in the lunar samples, most authors attempted to fit these results into their beliefs of what should have happened on the lunar surface. Such beliefs vary; they reflect various hypotheses. In some cases the authors believe that the amino acids could not exist on the lunar surface ${ }^{5,6,10}$ since they would decompose ${ }^{12}$. These authors would then interpret their experimental results in which they have found only a small amount of the amino acids as negative ${ }^{5,6,10}$. In the cases of the positive identification of the amino acids in the lunar samples, some authors believe that the amino acids are not indigenous to the lunar surface but are brought in by the solar wind ${ }^{20}$, that they were formed from the lunar module rocket exhaust ${ }^{23}$, and that the amino acids may have been formed during the analysis of lunar samples ${ }^{24}$. In this paper we are concerned with a separation of the experimental evidence for the presence of the amino acids in the lunar samples, from such hypotheses. This is important since the quality of the measurements of the amino acids, however imperfect due to the equipment of the times, is still valid and can be used with some reservations about the sensitivity. On the other hand, the various hypotheses about the presence or absence of the amino acids on the lunar surface have generally not progressed above the stage of the hypotheses, and if any experimental results are available to support such hypotheses, they are typically preliminary and depend on the models that may be inadequate ${ }^{12}$. The most solid hypothesis on the presence of the amino acids on the lunar surface is that the amino acids should be expected, since they were previously found on the meteorites. In conclusion, the experimental data on the actual lunar samples are generally of more value than the interpretations. We now re-consider the experimental data in conjunction with the early instrumental methods that were previously used.

\subsection{A deeper look at the initial experimental results}

From the various references on the early analyses of the amino acid presence in the lunar samples, a pattern easily emerges, which was recognized early on. This pattern consistently and predictably shows that the ion-exchange chromatography method is more sensitive and can identify more amino acids, than the GC-MS method ${ }^{7}$. The amino acids that were found are glycine and alanine in the largest amounts, accompanied by the smaller amounts of other amino acids, such as glutamic acid, aspartic acid, serine, and threonine $e^{1-3,7-9}$. The GC-MS studies found glycine ${ }^{5,6,11}$, alanine $^{11}$, and some additional amino acids in the Apollo 14 samples ${ }^{11}$. The small amounts of these amino acids coupled with the hypothesis that amino acids must decompose on the lunar surface ${ }^{12}$, led the authors to consider these results negative. The GC-MS results were interpreted as indicating an extremely low (and thus non-existent) amount of amino acids, despite the contrary evidence obtained by the competing ion-exchange method, which has shown the presence of the amino acids at levels which were much larger and thus not negligible. The amino acid pattern was not the one that is usually found in other materials when contamination has occurred ${ }^{1}$. The GC-MS technique that was used has shown a rather low recovery of the control samples ${ }^{5}$. It was concluded from such amino acid recovery experiments that the amounts of free amino acids (those extracted with water) in lunar fines may be greater than those revealed by GC-MS method which was used ${ }^{10}$.The central problem of the old analyses of the lunar samples is that they were not well suited for the detection of the most abundant meteoritic amino acid, the $\alpha$-aminoisobutyric acid (Aib). Aib is sterically hindered and its reactivity towards ninhydrin and TFA is considerably lower that that of the protein amino acids. (Ninhydrin was used as the post-column colorimetric derivatizing agent in the ion-exchange chromatography ${ }^{1,3,8}$. TFA is the reagent used for the derivatization of the amino acids prior to the GS-MS analysis ${ }^{5}$ ). The Aib is predictably absent from the early analyses, but is present in the more recent analyses which utilize sensitive HPLC (high performance liquid chromatography) techniques ${ }^{20}$. The $\mathrm{D} / \mathrm{L}$ analysis of the amino acids that were detected by HPLC revealed that the free alanine and aspartic acid from the hot water extracts were entirely found as L-enantiomers, and it was concluded that it must have been the result of recent terrestrial microbial contamination. The logic for this conclusion, however, is unclear. How could only two amino acids be found as contamination, out of all other peptide amino acids? Nakagawa $e t$ 
al. ${ }^{34}$ studied the amino acid composition of cellular proteins and the exopolysaccharide slime protein of the cyanobacterium Microcystis aeruginosa K-3a. Table 1 shows that by relative abundances glutamic acid, aspartic acid, alanine, and glycine were the dominant amino acids found in both the cellular protein and in the EPS slime. These protein amino acids were found in almost equal amounts (\% dry weight). These Microcystis aeruginosa results are consistent with the Howe et al. ${ }^{35}$ data on the amino acid composition of bacterial cell walls of E. coli; Salmonella pullorum, $S$. derby, and $S$. senftenberg. It is very important to note in Table 1 that the dominant cellular protein amino acid (glutamic acid -12.3\%) of the Microcystis cells was not even four times more abundant as the dry weight $\%$ of $14^{\text {th }}$ amino acid detected (tyrosine $3.4 \%$ ). When these relative abundances are compared with the values measured for the amino acids detected in the lunar fines, it defies logic to conclude that the lunar amino acids detected could possibly have resulted from contamination by modern terrestrial bacteria. Examples of the distribution of amino

TABLE 1: Amino Acids in Cellular Proteins and EPS ${ }^{34}$ of Cyanobacteria and Lunar Fines ${ }^{20}$

\begin{tabular}{|c|c|c|c|c|}
\hline Amino Acid & $\begin{array}{l}\text { Cellular } \\
\text { Protein } \\
(w t \%)\end{array}$ & $\begin{array}{l}\text { EPS } \\
\text { Protein } \\
(\text { wt \%) }\end{array}$ & $\begin{array}{c}\text { Lunar Fines (ppb) } \\
\text { Extract (0 here is } 0.05 \\
\text { or less)+ Hydrolyzate }= \\
\text { Total (by HPLC, } \\
\text { sample 78421) }\end{array}$ & $\begin{array}{c}\text { Lunar Fines (ppb) } \\
\text { Extract }+ \text { Hydrolyzate }= \\
\text { Total (by Ion Exchange } \\
\text { Chromatography, sample } \\
72501 \text { ) }\end{array}$ \\
\hline Glutamic acid & 12.3 & 8.4 & D,L-: $0+0.2=\mathbf{0 . 2}$ & $0+0.7=\mathbf{0 . 7}$ \\
\hline Aspartic acid & 12.0 & 13.4 & $\begin{array}{l}\text { D-: } 0+0.4=\mathbf{0 . 4} \\
\text { L-: } 0.7+1.1=\mathbf{1 . 8}\end{array}$ & $0.1+0.7=\mathbf{0 . 8}$ \\
\hline Alanine & 10.3 & 10.9 & $\begin{array}{l}\text { D-: } 0+0.2=\mathbf{0 . 2} \\
\text { L-: } 1.1+1.2=\mathbf{2 . 3}\end{array}$ & $0.3+1.1=\mathbf{1 . 4}$ \\
\hline Glycine & 8.7 & 10.1 & $3.5+10.6=\mathbf{1 4 . 1}$ & $1.7+7.1=\mathbf{8 . 8}$ \\
\hline Leucine & 8.2 & 8.6 & & \\
\hline Threonine & 6.6 & 10.3 & & \\
\hline Serine & 6.6 & 8.6 & $\mathrm{D}, \mathrm{L}-: 0.5+0.9=\mathbf{1 . 4}$ & $0.1 \quad 0.3=\mathbf{0 . 4}$ \\
\hline Valine & 6.5 & 7.4 & & \\
\hline Isoleucine & 5.0 & 5.0 & & \\
\hline Proline & 4.9 & 5.2 & & \\
\hline Lysine & 4.4 & 3.2 & & \\
\hline Arginine & 4.4 & 1.7 & & \\
\hline Phenylalanine & 3.8 & 4.6 & & \\
\hline Tyrosine & 3.4 & 1.7 & & \\
\hline Methionine & 1.9 & 0.4 & & \\
\hline Histidine & 1.0 & 0.6 & & \\
\hline TOTAL \% & 100.0 & 100.0 & & \\
\hline
\end{tabular}

acids in the lunar fines from Table 1 show that glycine is the most abundant, followed by alanin ${ }^{20}$. The results of the modern analysis by the HPLC method (1996) quantitatively agree with an early analysis by the Ion Exchange Chromatography (1970s) ${ }^{20}$. These findings are representative of most of the available data ${ }^{1,8,9,20}$ in which glycine to alanine ratio is typically $2: 1$ or larger. The other amino acids are typically found in smaller amounts than glycine and alanine $e^{1,8,9,20}$. Some differences in the results are also expected since the lunar samples were not the same in all the 
studies. Since the residence time on the Earth for all lunar samples returned by the Apollo program has been no more than forty years, major protein amino acids that are missing when these samples were studied could certainly not have been lost by diagenetic changes or amino acid instability. Furthermore, the absence of these life-critical protein amino acids that are common in every living organism known on Earth, clearly establish that the amino acids detected in the lunar fines could not have resulted from modern biological contamination in the laboratory after the samples were returned to Earth. The possible bacterial contamination of the curated lunar samples was studied recently by a new method, which utilizes the presence of muramic acid and 3-hydroxy fatty acids as chemical markers, in conjunction with a highly sensitive gas chromatography-tandem mass spectrometry (GC-MS/MS) ${ }^{14,15}$. Only one sample was found to be contaminated. This method has a good potential use for search for bacteria in extraterrestrial samples. While the old analytical methods which were used for the original analyses of the lunar Apollo samples gave extremely interesting preliminary results, the studies should be repeated with more modern equipment, such as the one which was recently successfully used for the amino acid analyses of meteorites, namely liquid chromatography-time of flight- mass spectrometry ${ }^{16}$. This method has detection limit for the amino acids which is at least three orders of magnitude lower than the traditional GC-MS ${ }^{16}$. A new method for a nanoflow separation of amino acids for the analysis of cosmic dust is under development ${ }^{19}$, and it can be also used in the future for the analyses of the amino acids in the lunar samples.

\section{APPLICABILITY OF THE AMINO ACID RESULTS TO OTHER EXTRATERRESTRIAL BODIES}

If we separate the experimental results from various adjacent hypotheses, the conclusion from the search of the amino acids in the lunar samples is that the amino acids were found. The early methods, although they were not very sensitive, still reliably detected glycine and alanine, but the other amino acids, glutamic acid, aspartic acid, serine and threonine, were found in smaller amounts. Since a host of indigenous amino acids are present in CI and CM carbonaceous meteorites and since it is now well known that there are meteorites from the moon and Mars present on Earth today, it is reasonable to expect that amino acids should be present on many other extraterrestrial bodies, such as cometary nuclei and Mars. Much can be learned from the confusion in the results and interpretations in the search for the amino acids in the lunar samples. Different analytical techniques have different sensitivities and different drawbacks. These need to be tested extensively on the control samples, not only for identification, but for the recovery also.

\section{PORPHYRINS IN THE LUNAR FINES}

The search for porphyrins has resulted in a positive finding in a sample from Apollo 12 mission, at a sampling point which was removed from the lunar landing vehicle ${ }^{30}$. Three different porphyrin-type pigments were found which resembled free-base porphyrin and metal complexes of porphyrin ${ }^{30}$. The sample from the vicinity of the rocket engine showed fluorescence range which did not correspond to porphyrins and which was then attributed to the exhaust of the rocket engine ${ }^{30}$. The porphyrin-like pigments which were observed in the Apollo 11 samples were attributed again to the exhaust from the engine ${ }^{31}$. No porphyrin-like pigments were found in a sample from Apollo $14^{31}$. Negative findings were reported on the samples from Apollo 11, 12, $14^{32}$ and $15^{33}$ missions. The results by two groups, headed by Rho and Hodgson, differed. Rho has consistently reported negative results ${ }^{17}$. As in the case of the interpretations of the results for the lunar amino acids, hypotheses were abundant. Rho suggested that absorptions observed by Hodgson's group were due to the light scattering anomalies due to grating defects in the spectrofluorometer ${ }^{17}$. Hodgson pointed out that this was not valid since no positive results were obtained with the blank samples ${ }^{30}$ which served as negative controls. More sensitive contemporary methods would be of tremendous value in resolving this very important result. Moreover, the porphyrin-like compounds, which were suggested and in some cases have been detected, could be identified in more detail with the presently available equipment. Likewise, the fluorescent compounds that were formed in model experiments on the reactions of the engine exhaust, and which have not been fully identified, could also benefit from the modern analytical methods. We suggest that with the renewed interest in the moon, these early studies on amino acids and porphyrins in lunar fines that have been carefully protected in curation NASA/JSC should be repeated. 


\section{CONCLUSIONS}

Our analysis of the literature on the search for the amino acids in the lunar samples from the Apollo missions has shown that the old analytical techniques that were used, ion-exchange chromatography and GC-MS, have shown the presence of small amounts of the amino acids. When the amino acids were claimed not to be present, this was either because the less sensitive technique, GC-MS, was used, or because the authors believed that the small amounts of the amino acids were insignificant. The relative abundance of the amino acids reported in the lunar samples are entirely inconsistent with the amino acid composition of contaminants such as human fingerprints or modern proteins present in bacterial cells. The presence of the amino acids in the lunar samples was confirmed more recently with HPLC. We recommend that the studies of the lunar samples be repeated with more modern, sensitive equipment. This applies also to the studies on the search for porphyrins in the lunar fines, which have shown some positive results.

\section{REFERENCES}

[1] Hare, P. E., Harada, K., and Fox, S. W., “Analyses for amino acids in lunar fines”, Proc. Apollo 11 Lunar Science Conf., Vol. 2, pp. 1799-1803 (1970).

[2] Murphy, M. E., Sister, Modzeleski, V. E., Nagy, B., Scott, W. M., and Young, M., "Analysis of Apollo 11 lunar samples by chromatography and mass spectrometry: Pyrolysis products, hydrocarbons, sulfur, amino acids", Proc. Apollo 11 Lunar Science Conf., Vol. 2, pp. 1879-1890 (1970).

[3] Harada, K., Hare, P. E., Windsor, C. R., and Fox, S. W., "Evidence for compounds hydrolysable to amino acids in aqueous extracts of Apollo 11 and Apollo 12 lunar fines", Science, 173, 433-435 (1971).

[4] Gehrke, C. W., Zumwalt, R. W., Stalling, D. L, Roach, D., and Aue, W. A., "A search for amino acids in Apollo 11 and 12 lunar fines", J. Chromatogr., 59, 305-319 (1971).

[5] Gehrke, C. W., Zumwalt, R. W., Kuo, K., Rash, J. J., Aue, W. A., Stalling, D. L., Kvenvolden, K. A., and Ponnamperuma C., "Research for amino acids in lunar samples", Space Life Sciences, 3, 439-449 (1972).

[6] Gehrke, C. W., Zumwalt, R. W., Kuo, K., Ponnamperuma, C., and Shimoyama, A., "Search for amino acids in Apollo returned lunar soil”, Origins of Life, 6, 541-550 (1975).

[7] Fox, S. W., Harada, K., and Hare, P. E., "Amino acids from the Moon: Notes on meteorites", Sub-cellular Biochemistry, 8, 357-373 (1981).

[8] Fox, S. W., Harada, K., and Hare, P. E., "Accumulated analyses of amino acid precursors in returned lunar samples", Proc. Fourth Lunar Science Conf., Vol. 2, 2241-2248 (1973).

[9] Fox, S. W., Harada, K., and Hare, P. E., "Amino acid precursors in lunar fines from Apollo 14 and earlier missions", Proc. Third Lunar Science Conf., Vol. 2, 2109-2118 (1972).

[10] Gehrke, C. W., Zumwalt, R. W., Kuo, K. C., Ponnamperuma, C., Cheng, C-N., and Shimoyama, A., "Extractable organic compounds in Apollo 15 and 16 lunar fines", Proc. Fourth Lunar Science Conf.,Vol.2, 2249-2259 (1973).

[11] Gehrke, C. W., Zumwalt, R. W., Kuo, K., Aue, W. A., Stalling, D. L., Kvenvolden, K. A., and Ponnamperuma, C., “Amino acid analyses of Apollo 14 samples", Proc. Third Lunar Science Conf., Vol. 2, 2119-2129 (1972).

[12] Sagan, C., "The search for indigenous lunar organic matter", Space Life Sciences., 3, 484-489 (1972).

[13] Gehrke, C. W., Zumwalt, R. W., and Kuo, K., "Quantitative amino acid analysis by Gas-Liquid Chromatography", J. Agric. Food Chem., 19, 605-618 (1971).

[14] Fox, A., "Chemical markers for bacteria in extraterrestrial space", "The Anatomical Record", 268, 180-185 (2002).

[15] Kozar, M. P., Krahmer, M. T., Fox, A., Larsson, L, and Allton, J., "Lunar dust: A negative control for biomarker analyses of extraterrestrial samples?", Geochimica et Cosmochimica Acta, 65, 3307-3317 (2001).

[16] Glavin, D. P., Dworkin, J. P., Aubrey, A., Botta, O., Doty III, J. H., Martins, Z., and Bada, J. L., "Amino acid analyses of Antarctic CM2 meteorites using liquid chromatography-time of flight-mass spectrometry", Meteoritics \& Planetary Science, 41, 889-902 (2006).

[17] Eglinton, G., Maxwell, J. R., and Pillinger, C. T., "Carbon chemistry of the Apollo lunar samples", Topics in Current Chemistry, Vol. 44, "Cosmochemistry”, Springer-Verlag, Heidelberg, Germany, 1974, pp. 83-113.

[18] Gehrke, C. W., "Chromatography - The bridge to environmental, space and biological sciences", J. Chromatography library, Vol. 64, issue "Chromatography", pp. 69-97 (2001). 
[19] Martin, M. P., Glavin, D. P., and Dworkin, J. P., 'Nanoflow separation of amino acids for the analysis of cosmic dust", Lunar and Planetary Science XXXIX, 2055 (2008).

[20] Brinton, K. L. F., and Bada, J. L., "A reexamination of amino acids in lunar soils: Implications for the survival of exogenous organic material during impact delivery", Geochimica et Cosmochimica Acta, 60, 349-354 (1996), and the references cited therein.

[21] Gehrke, C. W., "Gas-Liquid Chromatography in lunar organic analysis", Space Life Sciences, 3, 342-353 (1972).

${ }^{[22]}$ Gehrke, C. W., Zumwalt, R. W., Aue, W. A., Stalling, D. L., Duffield, A., Kvenvolden, K. A., and Ponnamperuma, C., "Carbon compounds in lunar fines from Mare Tranquillitatis - III. Organosiloxanes in hydrochloric acid hydrolysates", Proc. Apollo 11 Lunar Science Conference, Geochimica et Cosmochimica Acta Suppl., Vol. 2, pp. 1845-1856 (1970).

[23] Hamilton, P. B., and Nagy, B., "Problems in the search for amino acids in lunar fines", Space Life Sciences, 3, $432-$ 438 (1972).

[24] Biemann, K., "In situ synthesis during organic analysis of lunar samples", Space Life Sciences, 3, 469-473 (1972).

[25] Hare, P. E., "Ion-exchange chromatography in lunar organic analysis", Space Life Sciences, 3, 354-359 (1972).

[26] Kvenvolden, K. A., "Review of methods used in lunar organic analysis: Extraction and hydrolysis techniques", Space Life Sciences, 3, 330-341 (1972).

[27] Flory, D. A., and Simoneit, B. R., "Terrestrial contamination in Apollo lunar samples", Space Life Sciences, 3, $457-$ 468 (1972).

[28] "Opening New Frontiers in Space", National Research Council of the National Academies, The National Academies Press, Washington, D. C., 2008, pp. 16-20.

[29] Saal, A. E., Hauri, E. H., Lo Cascio, M., Van Orman, J. A., Rutherford, M. C., and Cooper, R. F., "Volatile content of lunar volcanic glasses and the presence of water in the Moon's interior", Nature, 454, 192-195 (2008).

[30] Hodgson, G. W., Bunnenberg, E., Halpern, B., Peterson, E., Kvenvolden, K. A., and Ponnamperuma, C., "Lunar pigments: Porphyrin-like compounds from an Apollo 12 sample", Proc. Second Lunar Science Conf., Vol. 2, pp. 1865-1874, 1971.

[31] Hodgson, G. W., Kvenvolden, K., Peterson, E., and Ponnamperuma, C., "A quest for porphyrins in lunar soil: Samples from Apollo 11, 12 and 14", Space Life Sciences, 3, 419-424 (1972).

[32] Rho, J. H, Bauman, A. J., Cohen, E. A., Yen, T. F., and Bonner, J., "Analyses of the returned lunar surface fines for porphyrins", Space Life Sciences, 3, 415-418 (1972).

[33] Rho, J. H., Bauman, A. J., and Cohen, E. A., "Examination of Apollo 15 deep drill core samples and Apollo 16 surface fines for porphyrins", Abstracts of the Lunar and Planetary Science Conference, Vol. 4, p. 619 (1973).

[34] Howe, J. M., Featherston, W. R., Stadelman, W. J. and Banwart, G. J., "Amino acid composition of certain Bacterial cell-wall proteins", Appl. Microbiol. 13, 650-652, (1965).

[35] Nakagawa, M., Takamura, Y. and Yagi, O., "Isolation and characterization of the slime from a Cyanobacterium, Microcystis aeruginosa K-3A”, Agric. Biol. Chem., 51, 329-387, (1987). 